movement toward a patient's "right to know," the court said there was no such general movement in Australian law, and that any change in current law would have to be legislated. AMA president Keith Woollard said his organization has always believed that access to medical records was a matter for individual negotiation between patients and their doctors.
However, he added that "unrestricted access to records may not always be in the patient's best interest, particularly in cases where psychiatric illness is involved."

The implications of the High Court ruling are currently being reviewed by both the AMA and the federal government.

ELIZABETH BAN

Sydney, Australia

\title{
Arrests made in HIV blood scandal
}

The repercussions of the criminal investigation into Japan's HIV blood scandal, which left almost half of Japan's 4,000 hemophiliacs infected with HIV through the use of non-heat-treated blood products in the 1980s, are now being felt throughout the Japanese pharmaceutical industry, the government bureaucracy, and academia.

In October, Akihito Matsumura - a former official who headed the Ministry of Health's Biologics and Antibiotics Division between July 1984 and June 1986 - was arrested on suspicion of professional negligence resulting in death. $\mathrm{He}$ is accused of failing to order the withdrawal of non-heat treated blood products, despite allegedly knowing about the risks of HIV infection in November 1984. Matsumura, who resigned from the ministry in July, is the first ministry official to face criminal charges (an unprecedented action in Japan). Murder charges have also been filed against him in the Tokyo and Osaka Courts by the relatives of two victims.

Matsumura's is the latest in a series of arrests, including the current and two former presidents of Green Cross Corporation, the pharmaceutical company that had Japan's largest market share of non-heat-treated blood products during the 1980 s. They were arrested for allegedly continuing to promote the sale of non-treated blood products even after safer heat-treated products had been approved in 1985 .

In September, Takeshi Abe, former vice-president of Teikyo University and one of the scientists at the center of the scandal, was also arrested and charged with professional negligence. Abe was head of a ministry AIDS study group that recommended the continued use by hemophiliacs of non-heat-treated blood products in 1983.

Naoto Kan, Japan's controversial but extremely popular Minister of Health and Welfare, has helped bring to conclu- sion the large compensation settlements between hemophiliacs infected with HIV and the government and pharmaceutical companies (Nature Medicine 2, 498; 1996). He is now is playing a vital role in bringing the individuals (including bureaucrats) responsible for the tainted blood scandal to justice.

Kan's actions are indeed having an effect on the usual workings of the ministry. There is now greater public pressure (in addition to Kan's pushing) to make the ministry's decision-making process more transparent and accountable. Unfortunately, this is slowing down the decisionmaking process further, according to one ministry official. Officials used to a system of collective responsibility are nervous that they could be held criminally responsible for controversial decisions, he says. Furthermore, ministry officials are often rotated every second year to new positions, and some are trying to avoid making difficult decisions before their next rotation. As a result, some large foreign pharmaceutical companies are beginning to express concerns that the lack of leadership could burden the already laborious new drug approval process further, according to a senior industry analyst in Tokyo.

Although the current system desperately needs reform, there is no consensus on how to do it. One Japanese expert, giving advice to a committee set up by Kan to find ways to prevent another contaminated blood disaster, was so exasperated by Japan's poor record that he suggested the Japanese government ask the US Food and Drug Administration (FDA) to set up an office in Tokyo. Under his proposal, the ministry would only approve drugs already approved by the FDA. Furthermore, FDA would provide training and advice for Japan's drug approval experts.

Officials acknowledge the current difficulties, but hope once a planned new system is up and running, drug approval will be both quicker and more thorough.

\section{Sex changes to} resume in Japan?

The Japanese Society for Psychiatry and Neurology has decided to set up a special committee to draw up guidelines for the diagnosis and treatment of people seeking sex-change operations. This move follows a controversial decision last July by Saitama Medical University's ethics committee to approve sex-change operations under certain circumstances. The university's decision was prompted in turn by the request of two women for sex-change operations (the 性 women had received both psy- choanalysis and hormone treat転 ment at the university.)

The Japanese medical terminology for those who seek sex症 change operations says they are suffering from seitenkansho (left) or seibetsujikodoitsuseichogai, translated literally as "sex turn-around illness" or "sex self-identification deficiency." Such operations have not officially been done in Japan since 1969, when a gynecologist who conducted three male-to-female sexchange operations was found guilty of breaking the Eugenic Protection Law. The law prohibits the removal of an individual's reproductive ability through surgery or the application of X-rays without "good reason." Although the law is open to interpretation, Japanese individuals wanting sex-changes now go overseas.

Despite the approval, no operations have been conducted yet at Saitama Medical University. But the decision has led Japan's Ministry of Heath and Welfare to try to build a national consensus on the issue. Ministry officials have called on the society to issue guidelines for the diagnosis and treatment of transsexuals. Once the guidelines have been issued, by the middle of next year, the Ministry of Health and Welfare will consider its own position as well as elaborating the legal implications entailed by a sex change.

R.N.

A new system for scientific evaluation of new drugs by teams of permanent experts, modeled on the FDA, and the review of phase II and phase III clinical trials data (which are not conducted in Japan at present) is also proposed .

RICHARD NATHAN Tokyo, Japan 